\title{
Correction to: Energy and exergy analysis and emission reduction from forced draft gasifier cookstove models: a comparative study
}

\author{
Himanshu' ${ }^{1}$ K. Pal ${ }^{2}$. Sanjeev Jain ${ }^{3}$. .S. K. Tyagi ${ }^{1}$
}

Published online: 4 February 2022

○) Akadémiai Kiadó, Budapest, Hungary 2022

\section{Correction to: Journal of Thermal Analysis and Calorimetry https://doi.org/10.1007/s10973-021-11137-y}

Unfortunately, in the original version of the article, the term exergy in the article has been written as energy due to typo error throughout the paper. Figure 12 was also published incorrectly in the original version. The corrected Fig. 12 is given in this correction.

The original article has been corrected.

The original article can be found online at https://doi.org/10.1007/ s10973-021-11137-y.

S. K. Tyagi

sudhirtyagi@yahoo.com

1 Department of Energy Science and Engineering, Indian Institute of Technology Delhi, Hauz Khas, New Delhi 110016, India

2 Department of Chemical Engineering, Indian Institute of Technology Delhi, Hauz Khas, New Delhi 110016, India

3 Department of Mechanical Engineering, Indian Institute of Technology Delhi, Hauz Khas, New Delhi 110016, India 

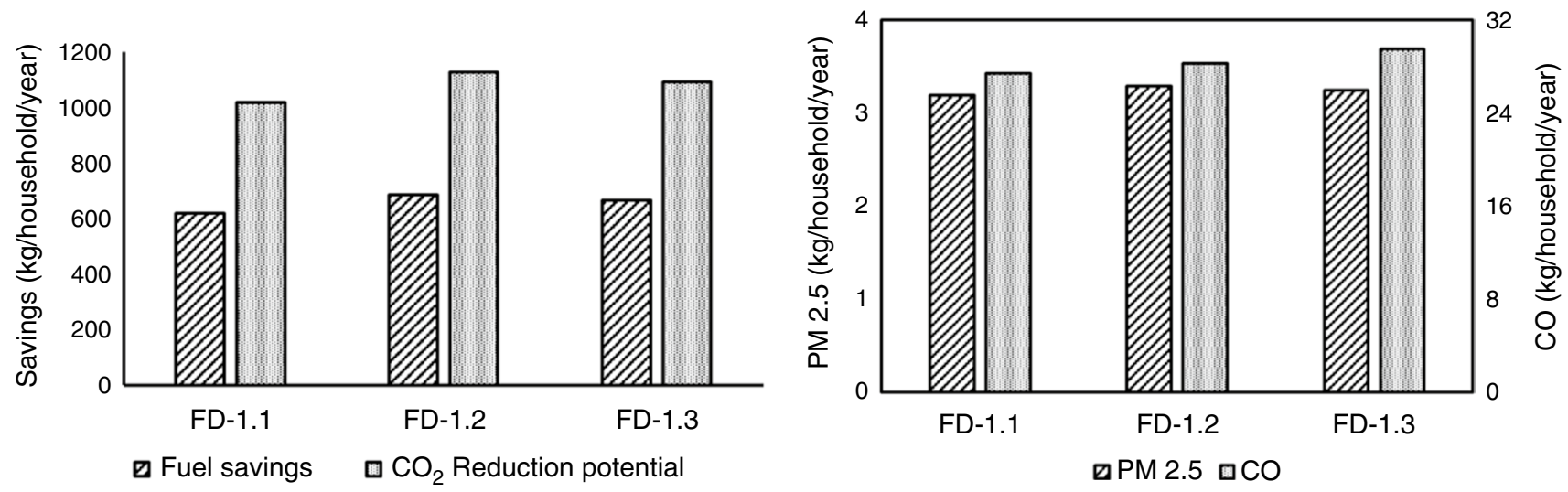

Fig. 12 Annual fuel savings and emission reduction potential of CO, PM 2.5 and CO2 from forced draft cookstove models

Publisher's Note Springer Nature remains neutral with regard to

jurisdictional claims in published maps and institutional affiliations. 